\title{
C. Von Dr. Krüper neu aufgefundene Arten
}

beschrieben von

Dr. G. Kraatz.

Homaetarsus Chaudoiri, die von Hochhuth im Bulletin de la Soc. imp. d. Natur. de Moscou von 1851 III. p. 34 nach armenischen Stücken aufgestellte ansebnliche Staphylinen-Gattung ist von Dr. Krüper in Griechenland aufgefunden und hier als besonders interessant für die europäische Fauna hervorzuheben. Die beiden Exemplare stimmen genau mit einem aus Beyrut überein, welches mir H. Baudi mittheilte. Der Käfer ist noch gröfser als die grofsen amerikanischen Cryptobium und von dieser Gattung dadurch leicht zu unterscheiden, dafs das letzte Glied der Maxillartaster halb so lang als das vorhergehende, nicht ganz klein und fein ist.

Anthaxia melancholica: Nigro-subviolacea, supra subopaca subtus parum nitida, omnium parce subtiliter griseo-pubescens, antennis brevibus, crassiusculis, thorace aequali, medio elytris paulo latiore, his pone medium distinctius acuminatis. - Long. 4-4 $\frac{1}{2}$ lin.

Durch ihre Grölse und dunkele Färbung leicht kenntlich, bald etwas kleiner, bald eben so grofs als selbst die gröfseren Stücke der Anth. manca, aber von anderer Gestalt, das Halsschild etwas breiter, die Flügeldecken etwas schmäler und gewölbter, hinter der Schulterschwiele deutlich eingezogen, hinter der Mitle ziemlich stark verengt, an der Spitze schräg nach innen abgeschnitten. Die Fühler sind kürzer und namentlich breiter als bei der A. manca, Glied 2 kaum länger als breit, 3 etwas länger, nach der Spitze zu deutlich erweitert, die folgenden, mit Ausnahme des kleines Endgliedes, doppelt so breit als lang. Der Kopf ist fein, maschig punktirt. Das Halsschild ist deutlich breiter als lang, vor der Mitte etwas breiter als die Flügeldecken, an den Seiten vor der Mitte derartig abgerundet, dafs erst hinter der Mitte ein deutlich kantig abgesetzter Seitenrand bemerkbar wird; vorn jederseits kaum, hinten deutlicher ausgebuchtet, oben fein maschig punktirt, in der Mitte mit einer schwachen Spur einer glatlen, kaum etwas vertieften Längslinie Das Schildchen zeigt vorn einen leichten Quereindruck. Die 
Flügeldecken sind fein reibeisenartig punktirt. Ein bläulicher Erzschimmer tritt oben wenig, auf der Unterseite deutlich hervor.

In einigen Exemplaren von H. Dr. Krüper in Griechenland aufgefunden.

Der Käfer läfst sich nicht ohne Weiteres in eine der Gruppen, in welche H. v. Kiesenwetter die Gattung Anthaxia in den Insekten Deutschlands (IV. Liefer. 1.) getheilt hat, unterbringen; er schliefst sich durch Gröfse und ebenes Halsschild zunächst an die Arten der Gruppe $\boldsymbol{B}$., weicht aber von ihnen dadurch ab, dafs das Halsschild deutlich breiter als die Flügeldecken wird, der Körper kurz und fein, nicht wollig behaart ist.

Malachius graecus: Viridis, ore flavo, thoracis maculis angularibus elytrisque apice coccineis, articulo tertio quarto majore, summo apice acuminato, basi externe processu acuminato, retrorsum vergente. - Long. $2 \frac{3}{4}$ lin.

Malachius andalusicus v. Ki es enw. Berl. Ent. Zeischr. III. p. 31.

So grofs, aber ein wenig schlanker als Malach. bipustulatus, eben so gefärbt, die Männchen durch die Zeichnung des Kopfes und die Bildung der Fühler leicht zu unterscheiden; an den letzteren hat das 2te Glied beim $\sigma^{\nearrow}$ des bipustulatus innen einen so starken gelblichei Fortsatz, dafs er dem 5ten an Länge gleichkommt, beim graecus ist der gelbliche Fortsatz nur klein, und das 2te Glied viel kleiner als das 3te, während beim bipustulatus das umgekehrte Verhältnifs stattfindet. Das 3te Fühlerglied ist beim graecus nicht nur sehr kräftig, und erst an seiner vordern Hälfte verschmälert, sondern dadurch vor allen übrigen Arten ausgezeichnet, dafs es an seiner Basis einen dornförmigen, nach aufsen und unten gerichteten gelblichen Fortsatz besitzt; das vierte Glied ist wenig kleiner als das 3te, von der Mitte ab nach der Basalhälfte des Fühlers zu verschmälert; Glied 5 ist eher schwächer als beim bipustulatus, unten weniger gelblich, $6-9$ sind nach der Spitze etwas mehr erweitert als bei der genannten Art und mehr gelblich. Beim Weibchen sind die vier ersten Fühlerglieder nicht erweitert, das 2te und 3te unten deutlich gelb. Auf dem Kopfe tritt die gelbe Färbung nicht bis hinter die Basis der Fühler, sondern endet beinahe schon vor derselben, so dafs der Vorderrand der Augen von der Seite gesehen im grünen Felde steht, nicht im gelben, wie bei bipustulatus.

Da der Mal. graecus im Uebrigen grofse Aehnlichkeit mit dem bipustulatus zeigt, ist eine weitere Beschreibung kaum nöthig. 
Malachius lusitanicus Er., welchen v. Kiesenwetter nur aus der Beschreibung kannte, unterscheidet sich durch bläulich grüne Färbung, geringere Gröfse, Färbung des Kopfes und Bildung der Fühler, an denen das 3te Glied kürzer und schmäler ist als die einschliefsenden, an der Basis nach aufsen ohne Erweiterung. Auf dem Kopfe zieht sich beim $\delta$ die gelbe Färbung bis über die Fühlerba. sis hinauf (facie maris ultra antennas flava), so dafs der Vorderrand der Augen von der Seite gesehen auf gelbem Felde steht.

v. Kiesenwetter sammelte den Käfer in Aetolien und auch Dr. Krüper sandte ihn aus Griechenland ein.

Malachius tenellus (Sectio I.* Erichs.): Viridis seu viridicoeruleus, nigro-pilosellus, frontis parte anteriore anguste flavido, elytris apice coccineis, antennis gracilibus, articulis 4 primis subtus

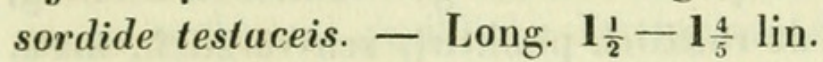

Kleiner als alle übrigen europäischen Arten aus der ersten Erichson'schen Hauptabtheilung der Gattung Malachius, welcher er angehört, kleiner und schmäler als die kleinsten Stücke des viridis, die Tarsen und namentlich die Fühler besonders schlank; die 4 oder 5 ersten Glieder an denselben sind auf der Unterseite mehr oder weniger schmutzig gelblich oder röthlich, einfach, nicht verdickt, so schlank wie bei den Weibchen des $M$. spinosus. Die Taster und der Kopf sind grün, die Stirn ist vorn nur in geringer Ausdehnung hell gefärbt; die gelbliche Färbung zieht sich seitlich nicht bis zum Vorderrande der Augen, so dafs der letztere nicht von einer gelben Stelle begränzt wird, was beim $\boldsymbol{M}$. spinosus der Fall ist. Das Halsschild ist ähnlich gebaut wie bei dieser Art, in den Hinterecken mit einem kaum bemerkbaren, kleinen, gelblich durchscheinenden Fleckchen; die Oberseite weniger fein greis behaart als beim spinosus, aufserdem mit längeren, abstehenden, schwarzen Haaren besetzt, ebenso die Flügeldecken, welche an der Spitze einen mäfsig grofsen rothen Fleck zeigen. Die Tarsenglieder sind besonders schlank, die Epimeren des Mesothorax schmuzzig gelb.

Die beiden von Dr. Krüper gefundenen Exemplare dieses zierlichen Malachius, mit einfacher Spitze der Flügeldecken, bin ich geneigt für ein Pärchen zu halten; hiernach würde sich die Art an M. viridis anreihen. 
Helops giganteus: Elongalus, leviter convexus, nitidulus, aenescenti-subcoeruleus, antennis capite thoraceque fere nigris, his subopacis, vix coerulescentibus, confertim fortiter punctatis, elytris punctato-striatis, singulo mucronem terminato, striis basi fortius impressis, interstitiis parce subtiliter punctatis. - Long. 15 lin.

Durch seine Gröfse vor allen bekannten Arten sehr ausgezeichnet, noch bedeutend gröfser als der syrische Helops Peyronis Reiche, von schwärzlich violetter Farbe, nur matt glänzend, mit schwarzem Erzschimmer. Der Körper sehr gestreckt, das Halsschild also im Verhälınifs zu den Flügeldecken kurz zu nennen. Die Fühler sind ziemlich gestreckt, nicht ganz von balber Körperlänge, schwarz, matt, mit schwachem blauen Anfluge. Glied 3 fast so lang als die 3 folgenden zusammen genommen, 4-8 gleich lang, die 3 letzten allmälig etwas kürzer. Der Kopf ist von der gewöhnlichen Bildung, dicht und kräftig, hier und da runzlich punktirt, schwärzlich, matt, vorn mit schwach bläulichem Anfluge. Das Halsschild ist kaum breiter als lang, seitlich sanft gerundet, vorn gerade abgeschnitten, neben den Hinterecken leicht ausgerandet, diese fast rechtwinklig, die Vorderecken stumpf, leicht abgerundet, die Oberseite nur flach gewölbt, dicht und kräftig punktirt, die Punkte vor dem Hinterrande etwas weniger dicht, schwarz, fast ohne Glanz, mit sehr geringem blauen Anfluge. Das Schildchen ist verhältnifsmälsig grofs, ziemlich dicht punktirt. Die Flügeldecken sind am Grunde etwas breiter als das Halsschild, namentlich hinter der Mitte (etwa wie beim $\boldsymbol{H}$. lanipes) verbreitert, mit leichtem Glanz und schwach violett-erzfarbenem Anfluge, hinten jede einzeln spitzig ausgezogen, Nath und Aufsenrand an der Spitze schwielig erhöht; in den Punktstreifen stehen die Punkte nicht ganz dicht und werden nach hinten allmälig feiner, nach der Basis zu (namentlich in den mittleren) stärker, und fliefsen stellenweise zusammen; die Zwischenräume sind weitläufig punktirt. Die Beine sind mäfsig gestreckt, deutlich blau angeflogen.

In einigen Exemplaren von Dr. Krüper auf dem Taygetos in alten Baumstümpfen aufgefunden.

Stenostola alboscutellata '): Nigra, elytris vix coerulescentibus, opacis, densius griseo-pubescentibus, confertim punctatis, scutello densissime albido-pubescente. - Long. 6 lin.

1) Im Gegensatz hierzu mufs die Diagnose der Sten. nigripes etwa auten: Nigra, elytris coerulescentibus, nitidulis, tenuiter pubescentibus, cre- 
Gröfser als die gröfsten mị vorliegenden deutschen Stenostola, namentlich in den Flügeldecken gestreckter, durch die dichtere und feinere Punktirung, dichte und feine graue Behaarung derselben, welche sie ganz matt erscheinen läfst, und die dichte schneeweifse Behaarung des Schildehens (namentlich bei den 우) von der St. nigripes merklich unterschieden, im Uebrigen derselben nahe verwandt. Gegen 20 Exemplare zeigten keine Uebergänge zur St. nigripes.

Anmerk. Eine aus dem südlichen Deutschland oder wahrscheinlicher aus Dalmatien stammende Stenostola (q) in meiner Sammlung hat die Gestalt der nordischen Sten. nigripes, aber viel feiner punktirte Flügeldecken, ohne den eigenthümlichen Erzglanz, welche z. B. die Dresdener, Berliner und schwedischen Exemplare zeigen. Nach ähnlichen Stücken hat wahrscheinlich Küster seine Stenostola nigripes, als Stenost. Tiliae (Käf. Europ. VII. 59.) dagegen wohl nur weibliche Exemplare der typischen Stenost. nigripes Fabr. aus Siebenbürgen beschrieben; das breite Brustschild derselben (richtiger den schmäleren Kopf) und die dichter behaarten Ränder der Bauchsegmente, welche die Weibchen auszeichnen, fafst Küster mit Unrecht als specifische Eigenschaften auf.

Stellen sich, wie ich vermuthe, mein Stück und die Küsterschen Exemplare seiner nigripes mit, ,schieferschwarzen Flügeldekken" als Varietät meiner alboscutellata heraus, so wäre bei derselben nigripes $\mathrm{Küster}$ als synonym zu citiren.

Die Synonymie lautet hiernach folgendermafsen:

Stenostola nigripes $\mathrm{F}$ abr.

$$
\begin{aligned}
& \text { T ferrea Schrank, Panz. } \\
& \text { \& Tiliae Küster. }
\end{aligned}
$$

Stenostola alboscutellata $\mathrm{K}$ raatz. v.? nigripes Küster.

bre fortius punctatis, scutello griseo- seu albido-pubescente. - Long. $3 \frac{1}{2}-$ $5 \frac{1}{2}$ lin.

Gyllenhall, Mulsant und Andere führen in der Diagnose der Art an, dafs der Thorax jederseits eine weifs behaarte Längslinie zeigt, welche nach $\mathrm{MI}$ ulsant bei seiner Var. $\boldsymbol{A}$. der $S$. ferrea $\mathrm{S}$ chrank fehlt; soweit ich indessen beobachtet habe, sind die weifsen Binden ein Geschlechtskennzeichen und kommen ausschliefslich den Weibchen zu, fehlen den Männchen; dafs abgeriebene Weibchen bisweilen nur noch eine schwache Spur von einer Binde zeigen, ist natürlich. Bei den Männchen erscheint zugleich der Kopf im Verhältnifs zum Halsschilde viel breiter, was hauptsächlich von den gröfsern, mehr vortretenden Augen herrührt. 
Obrium bicolor: Nigrum, parce pilosum, elytris testaceis, pedibus fuscis, femorum basi tibiisque anterioribus fere totis sordide testaceis. - Long. $2 \frac{3}{8}$ lin.

Kleiner, namentlich etwas flacher als Obrium brunneum, Kopf und Halsschild schwärzlich, im Verhältnifs zu den Flügeldecken etwas länger. Die Fühler sind ganz ähnlich gebaut wie beim brunneum, pechschwarz, Glied 3 kaum, 5 deutlich länger als 4 . Der Kopf ist im Verhältnifs etwas schmäler als beim brunneum, da die Augen weniger stark vortreten; er ist dicht und fein, ziemlich verloschen punktirt, zwischen den Augen mit einer vertieften Längslinie. Der Bau des Halsschildes ist ähnlich wie bei Obrium, seine Oberseite ist mit einzelnen, längeren, bräunlichen Haaren besetzt, in der Mitte glatt und glänzend, an den Seiten äufserst fein pubescent. Das Schildchen ist deutlich, abgerundet, pechbraun. Die Flügeldecken sind hell braungelb, weitläufig und deutlich, aber nicht tief punktirt. Die Beine sind etwas kräftiger als bei brunneum, die Schenkel nach der Basis zu weniger stark verschmälert, schmutzig dunkelbraun, am Grunde pechbraun; diese Farbe zeigen auch die vorderen Schienen mit Ausnahme der Spitze. Der Hinterleib ist pechbraun, der Hinterrand der einzelnen Segmente rothbraun.

In einigen Stücken von Dr. Krüper in Griechenland gesammelt.

Stenoria thoracica: Nigra, elytris totis rufo-testaceis, nitidulis, ano rufo. - Long. $2 \frac{3}{4}$ lin.

Kaum gröfser aber gedrungener erscheinend als Sten. apicalis, durch das ganz schwarze Halsschild und die einfarbigen Flügeldekken auf den ersten Blick von ihr zu unterscheiden, die Fühler und Flügeldecken anders gebildet. Erstere sind bei dem mir vorliegenden (muthmafslich weiblichen) Exemplare wenig länger als bei $\mathbf{S t}$. apicalis , aber kräftiger, die ersten Glieder kürzer, die lełzten, namentlich das Endglied, gestreckter. Kopf und Halsschild sind ähnlich gebaut, wie bei der genannten Art, dicht und kräftig punktirt, letzteres etwas weniger dicht. Die Flügeldecken sind nach hinten viel weniger verschmälert als bei apicalis, ihr Aufsenrand viel weniger scharf abgesetzt, daher ähnlich gebaut wie bei $\boldsymbol{A}$ palus. Die Oberseite runzlig punktirt. Beine und Unterseite schwarz, das letzte deutlich bemerkbare, dreieckig ausgeschnittene Segment roth, an der Basis aber geschwärzt. 


\section{$2 \mathrm{BHL}$ Biodiversity Heritage Library}

Kraatz, G. 1862. "C. Von Dr. Krüper neu aufgefundene Arten." Berliner entomologische Zeitschrift / herausgegeben von dem Entomologischen Vereine in Berlin 6, 121-126.

View This Item Online: https://www.biodiversitylibrary.org/item/37790

Permalink: https://www.biodiversitylibrary.org/partpdf/36658

\section{Holding Institution}

Smithsonian Libraries

\section{Sponsored by}

Smithsonian

\section{Copyright \& Reuse}

Copyright Status: Public domain. The BHL considers that this work is no longer under copyright protection.

This document was created from content at the Biodiversity Heritage Library, the world's largest open access digital library for biodiversity literature and archives. Visit BHL at https://www.biodiversitylibrary.org. 